\title{
Nicotine withdrawal and accident rates
}

I $t$ is well known that when regular smokers quit smoking, their mood and cognitive performance typically deteriorate within a few hours of abstaining ${ }^{1,2}$. But do these psychological deficits, readily measured in the laboratory, cause major disruption in everyday activities, such as performance at work? Here we use a new method to address this question; our data suggest that the effects of nicotine withdrawal can indeed be detected in daily activities.

Since 1984, the second Wednesday of March has been known as No Smoking Day (NSD) in the United Kingdom. There is evidence $^{3,4}$ that a large number of smokers (up to 2 million) make an attempt to abstain from smoking, or smoke less, on this day. We therefore decided to test the hypothesis that nicotine withdrawal causes deficits in real-world psychomotor performance by comparing a measure of performance on NSD itself with performance on Wednesdays before and after NSD.

Our measure was the number of nonfatal accidents at work reported to the Health and Safety Executive in Great Britain in industries in which the executive is the enforcing authority. Workplace accidents resulting in a major injury, or in a person having to take more than three days off work, have, by law, to be reported to this body in Great Britain. The national Health and Safety Executive statistics are based on reports under the Reporting of Injuries, Diseases and Dangerous Occurrences Regulations.

Our assumptions were as follows: first, there will be many more people in the working population suffering from nicotine withdrawal on NSD itself than on Wednesdays before and after; and second, deterioration in psychological function as a result of nicotine withdrawal causes an increased chance of an accident at work.

\begin{tabular}{|c|c|c|c|}
\hline Day & 'Before' NSD week & NSD week & 'After' NSD week \\
\hline Monday & 695.9 (28.2) & $690.3(28.5)$ & $646.6(24.1)$ \\
\hline Tuesday & 593.3 (22.6) & 586.1 (19.8) & 555.4 (19.9) \\
\hline Wednesday & $553.4(17.6)$ & $575.8(16.7)$ & $519.1(18.2)$ \\
\hline Thursday & $546.8(16.7)$ & 529.4 (20.9) & 493.5 (19.3) \\
\hline Friday & $493.4(16.8)$ & 490.5 (23.4) & $443.5^{*}(20.1)$ \\
\hline
\end{tabular}

We compared the average number of reported accidents occurring during NSD week with the average for the two weeks before NSD week (our 'before' measure) and the average for the two weeks after NSD week (our 'after' measure). Table 1 shows the means and standard errors of these measures for the ten years (1987-96) for which daily data were available. Planned paired-sample Student's $t$-tests (one-tailed) indicated that there were significantly more reported accidents on NSD than on the Wednesday in the 'before' measure $(t(9)=$ $-2.15, P=0.03)$, or on the Wednesday in the 'after' measure $(t(9)=-5.95, P<0.001)$.

Visual inspection of data in Table 1 shows that, in contrast with NSD, there were actually fewer reported accidents on the Monday, Tuesday, Thursday and Friday in NSD week than on those days in the 'before' measure. This indicates that there was nothing about the week of NSD generally that was generating an excess of reported accidents. Moreover, although there are fewer reported accidents generally in the 'after' measure (perhaps because of better weather or more people being on holiday as spring progresses), the difference in the number of reported accidents on NSD compared with on the Wednesday in the 'after' measure is larger than for all the other days. Finally, there are also large day-of-the-week effects, for which there may be many underlying causes.

Of course, there may be some other factor associated with NSD that underlies the effect seen. It is difficult, however, to imagine what it might be, especially given that the actual date of NSD can vary between 8 and 14 March across years. We stress that the NSD effect, if real, should not be construed as indicating that cessation attempts on No Smoking Day are a bad idea, although it may suggest that wider use of nicotine replacement might be beneficial. Our findings could be tested with data from other countries (for example, from the Great American Smokeout) and by examining other variables for which accurate day-by-day data are available (such as road traffic accidents).

Andrew J. Waters

Tobacco Research Section,

National Addiction Centre, Institute of Psychiatry,

London SE5 8AF, UK

e mail: rmjdajw@ucl.ac.uk

Martin J. Jarvis, Stephen R. Sutton

ICRF Health Behaviour Unit,

Department of Epidemiology and Public Health,

University College London, London WC1E 6BT, UK

1. Snyder, F. R., Davis, F. C \& Henningfield, J. E. Drug Alcohol Dep. 23, 259-266 (1989).

2. West, R. J., Jarvis, M. J., Russell, M. A. H., Carruthers, M. E. \& Feyerabend, C. Br. J. Addict. 79, 215-219 (1984).

3. McGuire, C. Pausing for Breath: A Review of No Smoking Day Research 1984 to 1991 (Health Education Authority, London, 1992).

4. West, R. J. Getting Serious about Stopping Smoking: A Review of Products, Services, and Techniques. A Report for No Smoking Day (Health Education Authority, London, 1997).

5. A Guide to the Reporting of Injuries, Diseases, and Dangerous HMSO, London, 1986). Occurrences Regulations 1985 (Health and Safety Executive,

\section{Cause of sea fan death in the West Indies}

A fungus from the genus Aspergillus is the probable agent of epizootic infections that have caused mass mortality of sea fan corals (Gorgonia ventalina) over the past 15 years $^{1,2}$. Here we show that four strains of the fungus involved in these infections are members of the species Aspergillus sydowii, a common saprobe (an organism that lives on decaying matter) that is found in both terrestrial and marine environments. Isolates of A. sydowii taken from diseased sea fans caused new infections of sea fans in inoculation experiments, whereas isolates taken from elsewhere did not.

We took four fungal isolates from diseased sea fans in Saba, Trinidad, the Florida Keys, and San Salvador, Bahamas. We cultured the isolates on agar media and analysed them morphologically and by DNA sequencing. The sequence of the $18 \mathrm{~S}$ nuclear ribosomal small subunit gene was identical in three isolates tested, and was more similar to that of Aspergillus fumigatus than to any other sequence in GenBank ${ }^{2}$. All four isolates showed morphological characteristics typical of $A$. sydowii ${ }^{3,4}$, including the production of conspicuously echinulate asexual spores (conidia) and a distinctive turquoise-blue colony colour (Fig. 1).
To establish that these isolates were A. sydowii, we sequenced a $\sim 485$-base-pair portion of the $5^{\prime}$ non-translated region of the $\operatorname{trp} \mathrm{C}$ gene from three of the isolates that could reinfect sea fans (see below). We compared these sequences to those from known A. sydowii isolates from peanuts in Georgia (isolate H640), dates in Austria (NRRL 242), dried fish in Japan (NRRL 244) and silk thread in Philadelphia (NRRL 249) and to sequences from other closely related species (Aspergillus versicolor, Emericella nidulans and Emericella violacea).

We chose this sequence because it shows $3.8-5.4 \%$ variation between phenotypic sister species of Aspergillus (A. parasiticus and A. flavus) and a maximum of $2.2 \%$ varia- 


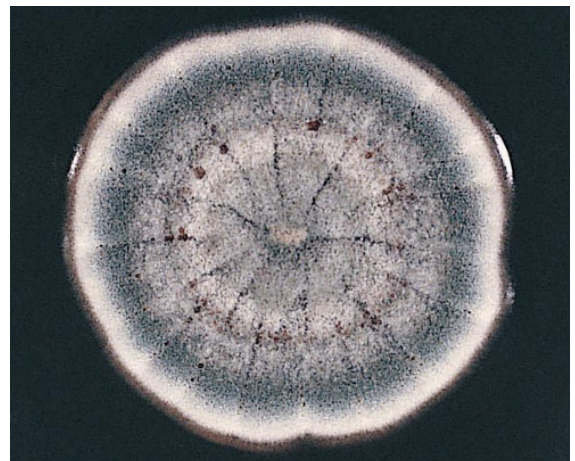

Figure 1 Colonial growth of the Saba sea fan pathogenic isolate in culture.

tion among isolates within a phenotypic species $(\text { A. flavus })^{5}$. A. versicolor was chosen because it is phenotypically nearly indistinguishable from $A$. sydowii, and E. nidulans and E. violacea were chosen as outgroups.

The sequences were subjected to maximum parsimony analysis, and all $A$. sydowii isolates and sea fan pathogenic isolates formed a strongly supported (100\% bootstrap) clade that was separate from $A$. versicolor and the Emericella outgroups, with no evidence for distinction between the known pathogenic isolates and A. sydowii isolates from non-marine sources (Fig. 2). Sequence divergence between the sea fan pathogenic and non-marine isolates showed a maximum of only $1.1 \%$ (representing six variable nucleotide sites), whereas it was a minimum of $10.1 \%$ between any of these isolates and $A$. versicolor isolate 226. We conclude that the fungus causing mortality of West Indian sea fans is A. sydowii.

A. sydowii is a common, cosmopolitan saprobic fungus not previously recognized to cause widespread disease in plants or animals. It has been isolated from a variety of terrestrial environments, including deglaciated soils in Alaska and various soils in tropical regions, as well as from many different plant materials ${ }^{6}$. In a survey of fungi that could be cultured from subtropical marine waters near the Bahamas and the Straits of
Florida, A. sydowii was found in both eulittoral zones and oceanic zones, and was isolated from waters collected as deep as 4,450 m (ref. 7). Many Aspergillus species, including A. sydowii, are tolerant of salt concentrations as high as, or higher than, those found in the marine environment.

To further test the virulence of $A$. sydowii, we used isolates from non-marine environments (NRRL 242, 244 and 249) and two isolates from sea fans (those from Saba and San Salvador $)$ to challenge small $(\sim 20 \mathrm{~cm}$ in height) G. ventalina colonies in flow-through seawater aquaria at the Bahamian Field Station in San Salvador. We directly inoculated sea fan colonies with pure A. sydowii cultures in separate experimental aquaria and inoculated colonies with sterile media in control aquaria. All replicates inoculated with the Saba and San Salvador isolates showed recession of coenenchyme at the point of inoculation, exposing the axial gorgonin skeleton (central core). These are typical signs of aspergillosis of sea fans $s^{2}$. This response did not occur in colonies inoculated with nonmarine strains of $A$. sydowii or in controls. We conclude that, under these conditions, isolates of A. sydowii taken from diseased sea fans possess pathogenic potential not seen in isolates taken from other sources.

Several Aspergillus species have a tendency to be opportunistic animal pathogens, generally striking individuals with compromised immune systems. The infection of West Indian sea fans by A. sydowii may also be opportunistic, owing to weakening of the host from stress imposed by pollution, other pathogens or environmental factors. The fact that non-marine isolates of $A$. sydowii failed to cause disease may reflect the presence of a specific pathogenicity factor in some isolates, perhaps a mycotoxin or other secondary metabolite. The virulence of A. sydowii isolates taken from the water column should be tested to determine whether pathogenic potential exists in all marine isolates. It should also be determined whether isolates of other Aspergillus species, many of which are commonly found in marine environments, are able to cause diseases of sea fans or other corals.

David M. Geiser ${ }^{\star}$, John W. Taylor

Department of Plant and Microbial Biology,

University of California, Berkeley,

California 94720, USA

e-mail: jtaylor@socrates.berkeley.edu

* Present address: Department of Plant Pathology,

204 Buckhout Laboratory,

The Pennsylvania State University,

University Park, Pennsylvania 16802, USA

e-mail:dgeiser@psu.edu

Kim B. Ritchie

Biology Department, University of North Carolina, Chapel Hill, North Carolina 27599, USA

e-mail:kritchie@mailserv0.isis.unc.edu

\section{Garriet W. Smith}

Department of Biology, University of South

Carolina-Aiken, Aiken, South Carolina 29801, USA

e-mail: garries@usca.usca.sc.edu

1. Nagelkerken, I. et al. in Proc. 8th Int. Coral Reef Symp. Vol. 1 (eds Lessios, H. A. \& Macintyre, I. G.) 679-682 (STRI, Panama City, 1997).

2. Smith, G. et al. Nature 383, 487 (1996).

3. Klich, M. A. \& Pitt, J. I. A Laboratory Guide to Common Aspergillus Species and their Teleomorphs (CSIRO Division of Food Processing, North Ryde, Australia, 1988).

4. Raper, K. B. \& Fennell, D. I. The Genus Aspergillus (Williams \& Wilkins, Baltimore, 1965).

5. Geiser, D. M., Pitt, J. I. \& Taylor, J. W. Proc. Natl Acad. Sci. USA 95, 388-393 (1998).

6. Domsch, K. H., Gams, W. \& Anderson, T.-H. Compendium of the Soil Fungi Vol. 1 (Academic, London, 1980). . Roth, F. J. et al. Can. J. Bot. 42, 375-383 (1964).

\section{Origins of Old \\ Testament priests}

According to Jewish tradition, following the Exodus from Egypt, males of the tribe of Levi, of which Moses was a member, were assigned special religious responsibilities, and male descendants of Aaron, his brother, were selected to serve as Priests (Cohanim). To the extent that patrilineal inheritance has been followed since sometime around the Temple period (roughly 3,000-2,000 years before present), Y chromosomes of presentday Cohanim and Levites should not only be distinguishable from those of other Jews ${ }^{1}$, but - given the dispersion of the priesthood following the Temple's destruction - they should derive from a common ancestral type no more recently than the Temple period. Here we show that although Levite Y chromosomes are diverse, Cohen chromosomes are homogeneous. We trace the origin of Cohen chromosomes to about 3,000 years before present, early during the Temple period.

We characterized Y-chromosomespecific variation at six microsatellites (repeats of short nucleotide sequences) and six presumably 'unique-event' polymorphisms (UEPs) in a sample of 306 male Jews 